\title{
Testing for Asymmetric Central Bank Preferences
}

\author{
Felix S. Nyumuah ${ }^{1}$ \\ ${ }^{1}$ Department of Financial Management, Zenith University College, Accra, Ghana \\ Correspondence: Felix S. Nyumuah, P.O. Box SK 237, Sakumono Estates, Tema, Ghana. Tel: 233-243-671-295. \\ E-mail: fsnyumuah@yahoo.co.uk or silverglw7@gmail.com
}

Received: December 22, 2017

Accepted: February 1, 2018

Online Published: February 28, 2018

doi:10.5539/ijef.v10n4p25

URL: https://doi.org/10.5539/ijef.v10n4p25

\begin{abstract}
The linear specification of the ideal monetary policy reaction function has been questioned in recent times by researchers. They have suggested a nonlinear framework where central banks exhibit asymmetric behaviours. Despite the important policy implications of having asymmetric central bank preferences, studies have been on single-country basis focusing almost entirely on advanced economies. The aim of this study is to check the existence of asymmetric preferences on the part of central banks in the context of a panel of countries and not just a single country. The study derives and estimates a nonlinear flexible optimal monetary policy rule, which permits zone-like as well as asymmetric behaviours using panel data from a range of countries both developed and less developed. Although the findings indicate the presence of asymmetric preferences on the output gap across less developed countries, generally, the evidence is in favour of a linear policy reaction function and symmetric central bank preferences. These findings mean that monetary policy is characterised by a linear policy rule and symmetric central bank preferences. The results also indicate that interest rate 'smoothing' reaction by monetary authorities is more pronounced in less developed countries than in developed ones.
\end{abstract}

Keywords: monetary policy, linear policy rule, nonlinear policy rule, symmetric preferences, asymmetric preferences

\section{Introduction}

Most Central Banks around the world are conducting monetary policy on the basis of inflation targeting. In such a framework, point targets or range targets for the inflation rate are announced to the public with the expectation of achieving long-run stable and low inflation. Examples of countries pursuing inflation targeting monetary policy are Australia, Canada, the Czech Republic, Sweden, New Zealand and the United Kingdom. Inflation targeting monetary policy is conducted using two alternative methods. Some central banks conduct monetary policy around a point target, while others aim at having inflation within a range. The Taylor rule and its extensions are the most widely used models to study the objectives of policy makers. In these models interest rates are considered linearly related to inflation and output gaps. It is assumed that there is a quadratic loss function for policymakers and the economy is characterised by a linear Phillips curve. In recent times, researchers have interrogated the linearity of the policy rule and have proposed a nonlinear form where central banks might show zone-like and asymmetric behaviours by reacting more vigorously to inflation when it is outside the target range than when it is within, and thereby alloting different weights to positive and negative deviations of inflation and output from their target values. Hence, this study investigates asymmetric central bank preferences.

There is an emerging literature which adopts the asymmetric preference specification as opposed to the quadratic preference one (Nobay \& Peel, 2003; Dolado, Maria-Dolores, \& Ruge-Murcia, 2004; Karagedik \& Lees, 2006; Surico, 2007; Cukierman \& Muscatell, 2008). With symmetric preferences the monetary authorities place equal weights on positive and negative deviations of inflation and output from their target values. Asymmetric preferences mean the central bank assigns different weights to downwards and upwards deviations of inflation and output from their expected values. In reality, it is more likely that policymakers will be more averse towards inflation than deflation. The result of having an asymmetric loss function is a nonlinear monetary policy reaction function.

The linear-quadratic (L-Q) framework has often been used to derive optimal rules to carry out monetary policy. The linear reaction functions or the Taylor rules depend on two important assumptions of a central bank 
quadratic loss function and a linear Phillips curve. However, questions have been raised recently about the two assumptions behind linearity in the literature. For example, Dolado, María-Dolores, and Naveria (2004), Qifa, Xufeng, Cuixia, and Xue (2015), Kumar and Orrenius (2016) investigate the issue about a nonlinear Phillips curve whereas Nobay and Peel (2003) and Ruge-Murciá (2003), and others, examine the assumption of a quadratic loss function. More recently, Komlan (2013), Santoro, Petrella, Pfajfar, and Gaffeo (2014), Anna Sznajderska (2014), Akdoğan (2015) and Rodrigo de Sáand Marcelo (2015) examine central banks asymmetric preferences.

Orphanides and Wieland (2000) derive optimal reaction functions based on the assumption of nonlinearity. A zone-linear type of Phillips curve is allowed whereby inflation is stable over a range of output gaps but changes outside this range. Boinet and Martin (2008) estimate a monetary policy model which permits a zone-like and asymmetric behaviour. Their results show that interest rates are not reactive as inflation approaches the target but the response becomes more and more vigorous as inflation moves away further from the target. Other studies that find empirical support for the existence of nonlinearity in monetary policy reaction functions are Bec, Salem, and Collard (2002), Martin and Milas (2004) and Kim, Osborn and Sensier (2005).

The main objective of this paper is to check the existence of asymmetric central bank preferences in the context of a panel of countries and not just a single country. Most of the studies about the asymmetric preferences and nonlinear monetary policy rule of the central bank have been single-country studies which focus mainly on developed countries. This study derives and estimates a nonlinear flexible optimal monetary policy rule which allows for both zone-like and asymmetric behaviours using panel data from a range of countries. The contribution of this study is therefore to provide evidence in support of or against asymmetric preferences, and nonlinear policy reaction functions of central banks across a variety of countries - both developed and less-developed and thus bridge the obvious gaps in the literature.

The rest of the study proceeds as follows. Section 2 presents the model and discusses the econometric methodology. The results of parameter estimates and tests of hypothesis are reported in Section 3. Finally, Section 4 ends the study with summary and conclusions.

\section{The Model and Econometric Testing}

The problem that is faced by the policymaker is to make a choice of the interest rate each period so as to minimise an intertemporal loss function with the IS and Phillips curves as constraints. Hence, the monetary policy reaction function is derived by solving this intertemporal optimisation problem.

\subsection{The Structure of the Economy}

Following Clarida et al (1999) the economy can be represented by the following equations of the New Keynesian Phillips curve and the aggregate supply curve.

$$
\begin{gathered}
\pi_{t}=\beta E_{t} \pi_{t+1}+\kappa y_{t}+e_{t} . \\
y_{t}=E_{t} y_{t+1}-\sigma\left(i_{t}-E_{t} \pi_{t+1}\right)+u_{t} .
\end{gathered}
$$

where $\pi_{t}$ is the rate of inflation and $y_{t}$ is the output gap. $E_{t} \pi_{t+1}$ and $E_{t} y_{t+1}$ are the expected values for inflation and for the output gap conditional on the information available at $\mathrm{t}, i_{t}$ denotes the nominal rate of interest, $u_{t}$ and $e_{t}$ represent a cost shock and a demand shock respectively. Finally, $\beta, \mathrm{k}$ and $\sigma$ are positive constants.

\subsection{The Monetary Authorities Asymmetric Preferences}

The problem that confronts the monetary authority is to make a choice of the interest rate at the commencement of the period $t$ based on the available information at the end of the previous period. The central bank makes an effort to choose the current interest rate $i_{t}$ and a series of future interest rates so as to minimise:

$$
E_{t-1} \sum_{\tau=0}^{\infty} \delta^{\tau} L_{t+\tau}
$$

subject to equations (1) and (2), where $\delta$ is the fixed discount factor. Following Surico (2007) the period loss function at time $t, L_{t}$, is specified by the linear exponential function:

$$
L_{t}=\lambda \frac{\mathrm{e}^{\gamma \gamma_{t}}-\gamma y_{t}-1}{\gamma^{2}}+\frac{\mathrm{e}^{\alpha\left(\pi_{t}-\pi^{*}\right)}-\alpha\left(\pi_{t}-\pi^{*}\right)-1}{\alpha^{2}}+\frac{\mu}{2}\left(i_{t}-i^{*}\right)^{2}
$$


where $\lambda$ is the relative weight on the output gap, which is denoted by $y$, and $\mu$ is the relative weight on the stabilization of the interest rate. $\pi^{*}$ represents the inflation rate target. $\alpha$ and $\gamma$ are parameters which capture any asymmetry in the central bank objective function. It is assumed that the monetary authority stabilises inflation around the constant inflation target, $\pi^{*}$, keeps the output gap near to zero and stabilises the nominal interest rate around its target, $i^{*}$. A negative value of $\gamma$ means the central bank prefers positive deviations of output to negative deviations. It can be seen that an output level less than the potential $\left(\mathrm{y}_{\mathrm{t}}<0\right)$ makes the exponential component of the loss function more than the linear component, the converse is true for an output level exceeding the potential $\left(y_{t}>0\right)$. The same reasoning applies to the coefficient $\alpha$. A negative value of $\alpha$ means the monetary authorities prefer positive deviations to negative deviations of inflation from target. However, if the central bank considers low inflation relative to the target to be more desirable than high inflation relative to the target, the value of of $\alpha$ would be positive. In Figure 1, a comparison is made between the standard quadratic with the linex function for both the inflation (see panel a) and the output (see panel b) objective. The linex function above is specified in such a way that it incorporates the quadratic form as a special case. If the L'Hô pital's rule is applied twice on (4), it can be shown that when both $\alpha$ and $\gamma$ tend to zero, $L_{t}$ reduces to the symmetric parametrization

$$
1 / 2\left[\left(\pi_{\mathrm{t}}-\pi^{*}\right)^{2}+\lambda \mathrm{y}_{\mathrm{t}}^{2}+\mu\left(i_{t}-i^{*}\right)^{2}\right]
$$
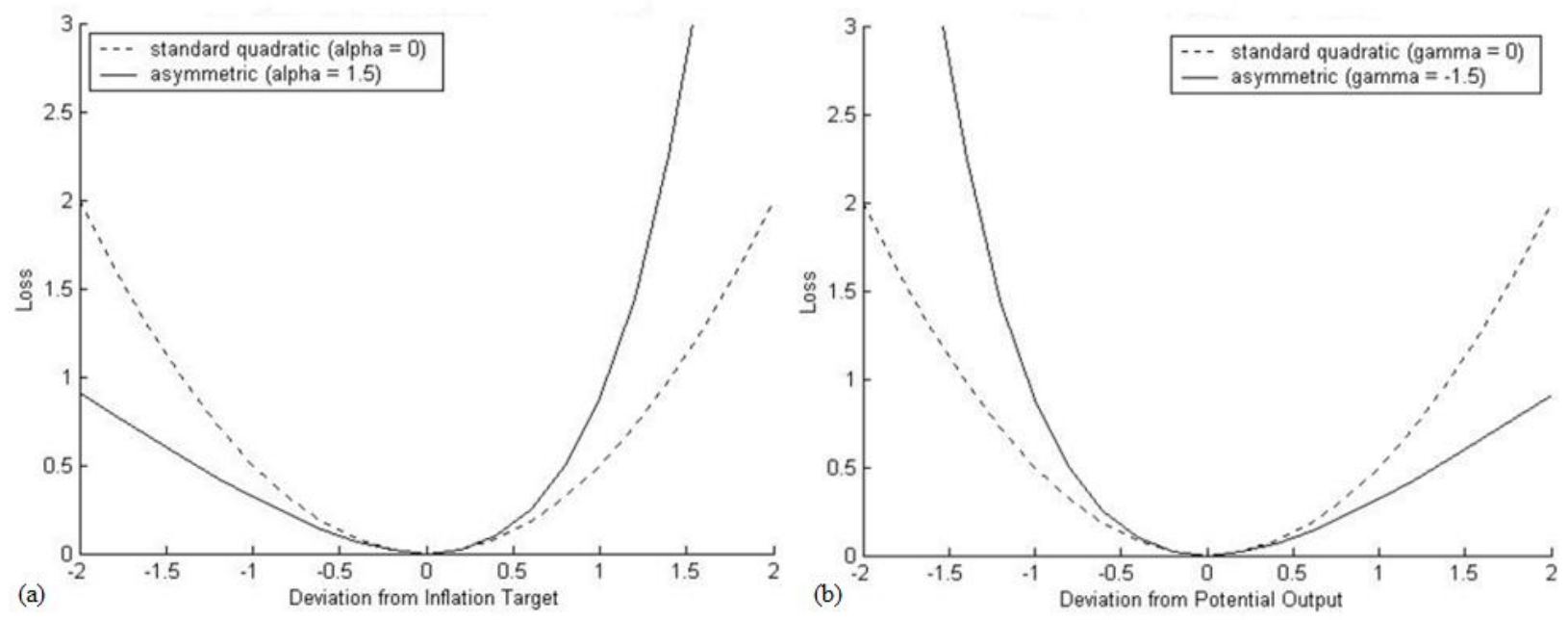

Figure 1. (a) Preference over inflation stabilisation and (b) Preference over output stabilisation

To derive the optimal monetary policy rule, it is assumed the monetary authorities choose policy rates in a discretionary manner. The policy maker chooses in each period the instrument $i_{t}$ so as to minimise

$$
E_{t-1}\left(\frac{e^{\left[x\left(\pi_{t}-\pi^{*}\right)\right]}-\alpha\left(\pi_{t}-\pi^{*}\right)-1}{\alpha^{2}}\right)+\lambda E_{t-1}\left[\frac{e^{\left(\gamma y_{t}\right)}-\gamma y_{t}-1}{\gamma^{2}}\right]+\frac{\mu}{2}\left(i_{t}-i^{*}\right)^{2}+F_{t}
$$

subject to $\pi_{t}=k y_{t}+f_{t}$ and $y_{t}=-\sigma i_{t}+g_{t}$, where $F_{t} \equiv E_{t-1} \sum_{t=1}^{\infty} \delta^{t} L_{1+t}, f_{t} \equiv \beta E_{t} \pi_{t+1}+e_{t}$ and $g_{t} \equiv E_{t} y_{t+1}+$ $\sigma E_{t} \pi_{t+1}+u_{t}$ are taken as given reflecting the fact that the monetary authorities cannot directly manipulate expectations.

The first order condition reads

$$
-E_{t-1}\left(\frac{e^{\left[\alpha\left(\pi_{t}-\pi^{*}\right)\right]}-1}{\alpha}\right) k \sigma-E_{t-1}\left(\frac{e^{\left(\gamma y_{t}\right)}-1}{\gamma}\right) \lambda \sigma+\mu\left(i_{t}-i^{*}\right)=0
$$

and it describes implicitly the nonlinear response of the central bank to the changes in the economy. Equation (5) incorporates the linear form as a special case and using the L'Hôpital's rule it can be shown that when both $\alpha$ and $\gamma$ tend to zero the reaction function reduces to an implicit interest rate rule of the type suggested by Taylor (1993).

$$
-k \sigma E_{t-1}\left(\pi_{t}-\pi^{*}\right)-\lambda \sigma E_{t-1}\left(y_{t}\right)+\mu\left(i_{t}-i^{*}\right)=0 .
$$


The hypothesis of symmetric central bank preferences can be tested by simply testing whether the structural parameters $\alpha$ and $\gamma$ of the interest rate reaction function are significantly different from zero.

\subsection{Econometric Testing for Symmetric Preferences}

To achieve the objectives of the study, the nonlinear reaction function (5) is estimated to assess if the parameters $\alpha$ and $\gamma$ are significantly different from zero. However, as Surico (2007) points out, the testing and estimation procedure appears complex because the null hypothesis does not restrict some essential parameters and so no deduction can be made any time the null hypothesis is true. The inflation and output gap terms in equation (5) become indeterminate when $\alpha$ and $\gamma$ are equal to zero. This implies that the null hypothesis of symmetric preferences does not restrict the complexities of parameters $\mathrm{k} \sigma / \mu$ and $\lambda \sigma / \mu$. It is impossible to estimate the coefficients $\mathrm{k}, \sigma, \lambda$ and $\mu$ separately using either the nonlinear specification (5) when $\alpha$ and $\gamma$ are not equal to zero or the linear form (6) when $\alpha$ and $\gamma$ are equal to zero. However, it is only possible to estimate the ratios $\mathrm{k} \sigma / \mu$ and $\lambda \sigma / \mu$. It is no longer possible to estimate the ratios on adoption of the nonlinear equation (5) when $\alpha$ and $\gamma$ are in fact equal to zero. This is because the inflation and the output gap terms in Equation (5) are not defined at $\alpha=\gamma=0$. Furthermore, Surico (2007) states that when the null hypothesis is valid, the estimation criterion is unaffected by the values of the inflation target, which is therefore an unidentified nuisance parameter.

To address these problems, the suggestion by Luukkonen, Saikkonen and Terasvirta (1988) is followed and the exponential terms in (5) are linearlised using a first-order Taylor series expansion. The resulting expression is then solved for $i_{t}$. Before the estimation, expectations are replaced with actual values and a lagged dependent variable capturing interest rate smoothing is introduced. Hence the following policy rule is used for the empirical analysis.

$$
i_{t}=c_{0}+c_{1} \pi_{t}+c_{2} y_{t}+c_{3} \pi_{t}^{2}+c_{4} y_{t}^{2}+\rho i_{t-1}+v_{t} .
$$

The coefficients $c_{i}$ with $i=0, \ldots, 4$ are convolutions of the structural parameters of the model whereas the error term is a linear combination of the forecast errors related to the predictions at time $t-1$ plus the rest of the Taylor series approximation. The restrictions $\alpha=\gamma=0$ imply $\mathrm{c}_{1} \neq 0, \mathrm{c}_{2} \neq 0$ and $\mathrm{c}_{3}=\mathrm{c}_{4}=0$. Hence, testing the hypothesis $\mathrm{H}_{0}^{I}: \mathrm{c}_{3}=\mathrm{c}_{4}=0$ in (7) is equivalent to testing the Hypothesis $\mathrm{H}_{0}: \alpha=\gamma=0$ in (5). The null of a linear reaction function is equivalent to the null of symmetric preferences and the test statistics, which is a $\chi^{2}$ distribution, can be assessed through a standard Wald test. Equation (7) is estimated using the Panel Generalised Methods of Moments (GMM) because of the endogeneity problem of regressors. The Ordinary Least Squares (OLS) estimates will be biased if the regressors are not exogenous. Following Newey and West (1987) the Panel GMM estimations are made with a Newey-West standard error correction for heteroscedasticity and autocorrelation (HAC) of unknown form. The set of instruments included are a constant, the second, third and fourth lag of inflation and the second and third lag of the output gap. With more instruments than parameters to estimate the J-statistics is used to test the validity of over-identifying restrictions.

\section{Empirical Results}

The test results as well as the estimates of the policy reaction function (7) are reported in this section. The analysis is carried out using quarterly data from six countries over the period 2002:1-2015:4. The data is obtained from the International Financial Statistics of the International Monetary Fund. However, the data for real GDP is annual GDP data at constant 2005 US\$, obtained from World Bank Development Indicators and converted to quarterly series in Eviews, using the constant-match average method. The output gap is constructed as the ratio of cycle output to trend output. The cycle and trend output estimates are obtained using the Hodrick-Prescott (HP) filter on the output data. The policy rate is used as a single rate to represent all interest rates. This is based on the assumption that all interest rates move with the policy rate. The core measure of inflation is calculated from the consumer price index as $100 \mathrm{x}\left(\mathrm{CPI}_{t}-\mathrm{CPI}_{\mathrm{t}-1}\right) / \mathrm{CPI}_{\mathrm{t}-1}$, where $\mathrm{CPI}_{\mathrm{t}}$ is the consumer price index for the period t. To check for the robustness of the baseline results, I also report the results for two alternative measures of inflation, namely the consumer price index inflation and the producer price index inflation.

\subsection{Baseline Estimates}

Table 1 reports the GMM estimates of Equation (7). The parameter $\mathrm{c}_{4}$ is not significant in all cases and has the expected negative sign for the less developed countries sample and the full sample. This implies the squared output gap does not exert a significant influence in controlling inflation. The negative coefficient on the squared output gap, $\mathrm{c}_{4}$, means the interest rate easing which accompanies reductions in output are larger than the tightening needed by output expansions of the same size, which is consistent with an asymmetric objective on the output gap. 
The parameter $c_{3}$ attached to the squared inflation, is also not statistically significant. This result implies that the hypothesis of a linear interest rate response to inflation is not rejected. The last but one row reports the p-values for the hypothesis of valid over-identifying restrictions. The results of the $\mathrm{J}$ test indicate that the over-identifying restrictions cannot be rejected at a significance level of $10 \%$. The coefficient of the lagged interest rate variable is significant for the less developed countries sample and the full sample but not significant for the developed countries sample. This implies interest rate "smoothing" reaction by the monetary authorities in less developed countries is higher than in developed economies.

Table 2 shows that the null hypothesis of a linear reaction function, which corresponds to the joint null of symmetric central bank preferences, is not rejected with the Wald statistics being less than the relevant critical values.

Table 1. Results of estimates of policy reaction function (core measure of inflation)

\begin{tabular}{|c|c|c|c|}
\hline & Less Developed Countries & Developed Countries & Full Sample \\
\hline \multirow[t]{2}{*}{$\mathrm{c}_{0}$} & 8.5347 & -1.0392 & 1.0746 \\
\hline & $(0.3208)$ & $(0.8266)$ & $(0.0536)$ \\
\hline \multirow[t]{2}{*}{$c_{1}$} & -8.6135 & 2.1270 & -0.5113 \\
\hline & $(0.4169)$ & $(0.5371)$ & $(0.6327)$ \\
\hline \multirow[t]{2}{*}{$c_{2}$} & 88.2038 & -30.5322 & -39.2298 \\
\hline & $(0.5611)$ & $(0.8815)$ & $(0.3847)$ \\
\hline \multirow[t]{2}{*}{$c_{3}$} & 1.7298 & -1.6910 & 0.4920 \\
\hline & $(0.4107)$ & $(0.5622)$ & $(0.2499)$ \\
\hline \multirow[t]{2}{*}{$\mathrm{c}_{4}$} & -2578.96 & 170.610 & -857.769 \\
\hline & $(0.5156)$ & $(0.9227)$ & $(0.4630)$ \\
\hline \multirow[t]{2}{*}{$\rho$} & 0.8922 & 1.2374 & 0.7909 \\
\hline & $(0.0000)$ & $(0.3871)$ & $(0.0000)$ \\
\hline $\mathrm{j}$-statistics (p-value) & 0.8350 & 0.3764 & 0.6117 \\
\hline Adjusted $\mathrm{R}^{2}$ & 0.3775 & 0.7638 & 0.9029 \\
\hline
\end{tabular}

Note. The probability values for coefficient estimates are reported in brackets.

Table 2. Wald test for symmetric preferences (the joint null hypothesis of $\alpha=\gamma=0$ )

\begin{tabular}{lccc}
\hline $\mathrm{W}(2)$ & Less Developed Countries & Developed Countries & Full Sample \\
\hline Core inflation & 0.8395 & 0.3559 & 1.8976 \\
Cpi inflation & 2.5442 & 0.9979 & 4.0242 \\
Ppi inflation & 2.2427 & 0.1117 & 1.1869 \\
\hline
\end{tabular}

Note. $\mathrm{W}(\mathrm{n})$ is the Wald test for $\mathrm{n}$ parameter restrictions, which is distributed as $\chi^{2}(\mathrm{n})$ under the joint null hypothesis $\mathrm{c}_{4}=\mathrm{c}_{5}=0$. The latter corresponds to the original null of symmetric central bank preferences, $\alpha=\gamma=0$. The joint null is rejected at the $1 \%$ significant level whenever $\mathrm{W}(2)>9.210$ and at the $5 \%$ level whenever $\mathrm{W}(2)>5.991$.

\subsection{Robustness Analysis}

The robustness of the results is assessed to other measures of inflation. Table 3 reports the estimates obtained with GMM using the consumer price index as a measure of inflation. The results are analogous to the baseline results presented in Table 1. Again the parameter $\mathrm{c}_{4}$ is not significant in all cases but has the expected negative sign for developed countries and the full sample instead of less developed countries and the full sample as found in Table 1 . The parameter $c_{3}$ is also not statistically significant for all cases except for the full sample where it is significant at the $10 \%$ level. Regarding the lagged interest rate variable, the results are consistent with the previous findings that it is significant for less developed countries and the full sample, but not significant for developed countries. The results of the $\mathrm{J}$ test still indicate that the over-identifying restrictions cannot be rejected 
at a $10 \%$ level of significance. Again, as shown in Table 2 the null hypothesis of a linear reaction function, which corresponds to the joint null of symmetric central bank preferences, is not rejected since the Wald statistics are less than the relevant critical values.

Equation (7) is re-estimated using the producer price index as a measure of inflation. The results are shown in Table 4 and they are quite consistent with the previous ones. Once again the parameter $\mathrm{c}_{4}$ is not significant in all cases, however, it has the expected negative sign for all cases. The parameter $c_{3}$ is also not statistically significant for all cases. Again, with respect to the lagged interest rate variable, the results are consistent with the previous ones implying that the incidence of interest rate "smoothing" reaction by monetary authorities in less developed countries is very high. As shown by the previous results, the $\mathrm{J}$ tests still indicate that the over-identifying restrictions cannot be rejected at a $10 \%$ level of significance. As shown in Table 2, the joint null hypothesis of symmetric central bank preferences is again not rejected, which is consistent with the previous results.

Table 3. Results of estimates of policy reaction function (CPI measure of inflation)

\begin{tabular}{lccc}
\hline & Less Developed Countries & Developed Countries & Full Sample \\
\hline $\mathrm{c}_{0}$ & -77.4382 & -240.3826 & -40.1167 \\
& $(0.2160)$ & $(0.4483)$ & $(0.1174)$ \\
$\mathrm{c}_{1}$ & 1.8337 & 5.2339 & 0.9351 \\
& $(0.2002)$ & $(0.4414)$ & $(0.1000)$ \\
$\mathrm{c}_{2}$ & -6.0614 & 35.4046 & -22.5960 \\
& $(0.7905)$ & $(0.4194)$ & $(0.3244)$ \\
$\mathrm{c}_{3}$ & -0.0104 & -0.0281 & -0.0053 \\
& $(0.1955)$ & $(0.4366)$ & $(0.0913)$ \\
$\mathrm{c}_{4}$ & 225.07 & -2678.59 & -686.32 \\
& $(0.8902)$ & $(0.3557)$ & $(0.5389)$ \\
$\rho$ & 0.7929 & 0.5182 & 0.9340 \\
& $(0.0000)$ & $(0.1842)$ & $(0.0000)$ \\
j-statistic(p-value) & 0.2174 & 0.2434 & 0.6303 \\
Adjusted R & 0.8161 & 0.6176 & 0.9381 \\
\hline
\end{tabular}

Note. The probability values for coefficient estimates are reported in brackets.

Table 4. Results of estimates of policy reaction function (PPI measure of inflation)

\begin{tabular}{lccc}
\hline & Less Developed Countries & Developed Countries & Full Sample \\
\hline $\mathrm{c}_{0}$ & -64.6812 & -485.5567 & 57.7398 \\
& $(0.5421)$ & $(0.7564)$ & $(0.7867)$ \\
$\mathrm{c}_{1}$ & 1.5785 & 10.5958 & -1.3480 \\
& $(0.5338)$ & $(0.7545)$ & $(0.7884)$ \\
$\mathrm{c}_{2}$ & -7.9614 & -25.2615 & -17.4568 \\
& $(0.6085)$ & $(0.9202)$ & $(0.6614)$ \\
$\mathrm{c}_{3}$ & -0.0091 & -0.0570 & 0.0076 \\
& $(0.5310)$ & $(0.7532)$ & $(0.7894)$ \\
$\mathrm{c}_{4}$ & -1611.82 & -5891.69 & -931.93 \\
& $(0.1575)$ & $(0.7420)$ & $(0.6560)$ \\
$\rho$ & 0.7633 & 0.7225 & 1.1445 \\
& $(0.0174)$ & $(0.3556)$ & $(0.0494)$ \\
j-statistic(p-value) & 0.3111 & 0.8684 & 0.7337 \\
Adjusted $\mathrm{R}^{2}$ & 0.8448 & -2.5984 & 0.8606 \\
\hline
\end{tabular}

Note. The probability values for coefficient estimates are reported in brackets.

\section{Conclusion}

Quite a large number of Central Banks have embraced inflation targeting as a method of monetary policy implementation. Some central banks conduct monetary policy around a point target, and others aim at having inflation within a target range. The most popular model used to analyse the decisions of monetary policy makers is the Taylor rule model with additions, which shows a linear relationship between the interest rate and inflation and output gaps. This agrees with the symmetric preferences assumption of central banks. With symmetric 
preferences the central bankers place equal weights on positive and negative deviations of inflation and output from their target values. Of late, researchers have questioned the linear specification and have suggested a nonlinear framework where central banks may show zone-like and asymmetric behaviours by responding more strongly to inflation when it is outside the target range than when it is within, and allotting different weights to positive and negative deviations of inflation and output from their target values.

Despite the important policy implications of having asymmetric central bank preferences studies have been on single-country basis focusing almost entirely on advanced economies. In contrast, this study examines the issue of asymmetric central bank preferences using panel data across a variety of countries both developed and less-developed.

Even though the findings indicate the presence of asymmetric preferences on output gap across less developed countries, generally, the evidence is in favour of a linear policy reaction function and symmetric central bank preferences. Accordingly, monetary policy is characterised by a linear policy rule and symmetric central bank preferences. Central banks attach equal weights to positive and negative deviations of inflation and output from their target values. The results also indicate that interest rate "smoothing" reaction by monetary authorities is more pronounced in less developed countries than in developed economies. These findings are robust across alternative measures of inflation.

The results imply that central banks adopt point targeting monetary policy. Conducting monetary policy around a point target means a higher volatility in inflation. With zone targeting inflation will be less volatile. This is because private sector decisions are based on their expectations about the activities of the central bank. Operating within a target zone reduces the effect of current shocks on expectations, because the private agents believe the central bank will only react to further shocks if the macroeconomic variables move outside the target zone. With more favourable inflation expectations, there will be a further decline in the volatility of inflation as the central bank's response to shocks within the target zone will be less.

When supply shocks occur, a central bank behaving in a discretionary manner within a band will act optimally by adjusting inflation in the direction of the shock so that there is not much variation in output. This is hardly possible if the central bank is committed to a pre-specified rate of inflation with no room for variation. Therefore, by adopting a linear rule the central bank may not be behaving optimally. Finally, the fact that interest rate smoothing is more pronounced in less developed countries means that these countries exercise enough caution in their interest rate adjustments to avoid economic shocks. It is recommended that future studies should increase the sample size by including more countries both developed and less-developed.

\section{References}

Akdoğan, K. (2015). Asymmetric Behaviour of Inflation around the Target in Inflation-Targeting Countries. Scottish Journal of Political Economy, 62(5), 486-504. https://doi.org/10.1111/sjpe.12089

Anna, S. (2014). Asymmetric effects in the Polish monetary policy rule. Economic Modelling, 36, 547-556. https://doi.org/10.1016/j.econmod.2013.09.045

Bec, F., Salem, M. B., \& Collard, F. (2002). Asymmetries in Monetary Policy Reaction Functions: Evidence for the U.S., French and German Central Banks. Studies in Nonlinear Dynamics and Econometrics, 6, 1-20. https://doi.org/10.2202/1558-3708.1006

Bernanke, B., Laubach, T., Mishkin, F., \& Posen, A. (1999). Inflation Targeting: Lessons from the International Experience. Princeton N.J.: Princeton University Press.

Boinet, V., \& Martin, C. (2008). Targets, Zones, and Asymmetries: A Flexible Nonlinear Model of Recent UK Monetary Policy. Oxford Economic Papers New Series, 60(3), 423-439. https://doi.org/10.1093/oep/gpn008

Clarida, R., Galì, J., \& Gertler, M. (1999). The Science of Monetary Policy: A New Keynesian Perspective. Journal of Economic Literature, 37, 1661-1707. https://doi.org/10.1257/jel.37.4.1661

Cukierman, A., \& Muscatelli, A. (2008). Nonlinear Taylor Rules and Asymmetric Preferences in Central Banking: Evidence from the United Kingdom and the United States. B.E. J. Macroeconomics, 8(7). https://doi.org/10.2202/1935-1690.1488

Dolado, J., Maria, D. R., \& Naveira, M. (2004). Are Monetary Policy Reaction Functions Asymmetric? European Economic Review, 49(2), 485-503

Dolado, J., Maria-Dolores, R., \& Ruge-Murcia, F. J. (2004). Nonlinear monetary policy rules: Some new evidence for the U.S. Studies in Nonlinear Dynamics \& Econometrics, 8(3). https://doi.org/10.2202/1558-3708.1155 
Karagedikli, O., \& Lees, K. (2006). Asymmetric monetary policy in Australia. Econ. Rec., 82, S85-S96. https://doi.org/10.1111/j.1475-4932.2006.00335.x

Kim, D. H., Osborn, D. R., \& Sensier, M. (2005). Nonlinearity in the Fed' s Monetary Policy Rule. Journal of Applied Econometrics, 20, 621-639. https://doi.org/10.1002/jae.792

Komlan, F. (2013). The asymmetric reaction of monetary policy to inflation and the output gap: Evidence from Canada. Economic Modelling, 30, 911-923. https://doi.org/10.1016/j.econmod.2012.09.046

Kumar, A., \& Orrenius, P. M. (2016). A closer look at the Phillips curve using state-level data. Journal of Macroeconomics, 47(Part A), 84-102. https://doi.org/10.1016/j.jmacro.2015.08.003

Luukkonen, R., Saikkonen, P., \& Terasvirta, T. (1988). Testing linearity against smooth transition autoregressive models. Biometrika, 75(3), 491-499. https://doi.org/10.1093/biomet/75.3.491

Martin, C., \& Milas, C. (2004). Modelling monetary policy: Inflation targeting in practice. Economica, 71(282), 209-221. https://doi.org/10.1111/j.0013-0427.2004.00366.x

Newey, W. K., \& West, K. (1987). A Simple, Positive Semi-Definite, Heteroskedasticity and Autocorrelation Consistent Covariance Matrix. Econometrica, 55, 703-708. https://doi.org/10.2307/1913610

Nobay, R., \& Peel, D. (2003). Optimal Monetary Policy in a Model of Asymmetric Central Bank Preferences. The Economic Journal, 113(489), 657-665.

Orphanides, A., \& Weiland, W. (2000). Inflation Zone Targeting. European Economic Review, 44(7), 1351-1387. https://doi.org/10.1016/S0014-2921(00)00033-7

Qifa, X., Xufeng, N., Cuixia, J., \& Xue, H. (2015). The Phillips curve in the US: A nonlinear quantile regression approach. Economic Modelling, 49, 186-197.

Rodrigo de Sá, \& Marcelo, S. P. (2015). Central bank and asymmetric preferences: An application of sieve estimators to the U.S. and Brazil. Economic Modelling, 51, 72-83.

Ruge-Murcia, F. J. (2003). Inflation Targeting under Asymmetric Preferences. Journal of Money, Credit and Banking, 35, 763-785. https://doi.org/10.1353/mcb.2003.0038

Santoro, E., Petrella, I., Pfajfar, D., \& Gaffeo, E. (2014). Loss aversion and the asymmetric transmission of $\begin{array}{lllll}\text { monetary policy. Journal of Monetary Economics, } & \text { 68, }\end{array}$ https://doi.org/10.1016/j.jmoneco.2014.07.009

Surico, P. (2007). The Fed's monetary policy rule and U.S. inflation: The case of asymmetric preferences. Journal of Economic Dynamics and Control, 31, 305-324. https://doi.org/10.1016/j.jedc.2005.11.001

Taylor, J. B. (1993). Discretion versus policy rules in practice. Carnegie-Rochester Conference Series on Public Policy, 39(0), 195-214. https://doi.org/10.1016/0167-2231(93)90009-L

\section{Copyrights}

Copyright for this article is retained by the author(s), with first publication rights granted to the journal.

This is an open-access article distributed under the terms and conditions of the Creative Commons Attribution license (http://creativecommons.org/licenses/by/4.0/). 